\title{
The Relationship between the Increase Rate of Downward Long-Wave Radiation by Atmospheric Pollution and the Visibility
}

\author{
By Takayuki Saito \\ Saitama Institute of Technology, Okabe, Saitama, Japan \\ (Manuscript received 20 August 1980, in revised form 25 December 1980)
}

\begin{abstract}
The downward radiation from the pollutants is extremely small compared with those from the water vapor and the carbon dioxide, and so it is quite difficult to estimate the effect of the pollutants on the downward long-wave radiation from the value of downward radiation in a city measured by the ordinary radiometer. However, since within the range of the wave length where the emissivity of the radiation of the water vapor is small, the additional radiation from the pollutants becomes relatively large to the radiation from the water vapor, the detection of the additional radiation can be expected to be relatively easy.

On this understanding, we have measured the downward radiation from the direction of zenith above the central part of Tokyo at a cloudless night, using a cylindrical radiometer which can sense the radiation of the wavelength between $8-17 \mu \mathrm{m}$. As a result, we have observed a conspicuous increase in radiation which can be considered to have been caused by the pollutants, and we have also determined the relationship between the ratio of increase in the radiation from the zenith and the visibility.

Furthermore, we have calculated and determined the relationship between the increase rate of the flux $\mathrm{f}$ the long-wave radiation from all the directions and the visibility, based on the result of the aforementioned observation. According to the result of this calculation, when the visibility is more than $32 \mathrm{~km}$, the effect of the radiation by the pollutants has not been recognized, but the flux of the downward radiation has increased as the visibility has fallen, and the ratios of increase, for example, have been $1.3 \%, 2.8 \%$ and $6.0 \%$ when the visibilities have been $20 \mathrm{~km}, 10 \mathrm{~km}$ and $2 \mathrm{~km}$ respectively.
\end{abstract}

\section{Introduction}

It has been presumed from some time ago that the downward radiation in the urban district can be increased by the effect of the pollutants, such as industrial gases and aerosols in the atmosphere, and they have conducted measurements in order to examine if this is true. According to the calculation by Yamamoto (1957), the average downward radiation from the aerosols in large cities is less than $1 \%$ of those from the water vapor and carbon dioxide. Fujimoto (1975) compared the downward radiation by the radiation chart with its measured value, and came to a conclusion that the additional radiation in the case of Tokyo is about 3\% of the downward radiation by $\mathrm{H}_{2} \mathrm{O}$ and $\mathrm{CO}_{2}$. Also, according to
Aida and Yaji (1979) who have measured the downward radiation in Tokyo and its suburban district at nighttime, the value of downward radiation measured in the central part of Tokyo is larger than that measured in suburban district by 8 to $10 \%$, and they have concluded that such difference in downward radiation results from the difference in temperature between the abovementioned two places. However, the magnitude of the additional radiation from the pollutants has not been clarified yet even today.

The purpose of this research is to clarify the relationship between the ratio of increase in the long-wave downward radiation flux by the pollutants and the visibility that is closely related with the concentration of the pollutants. 


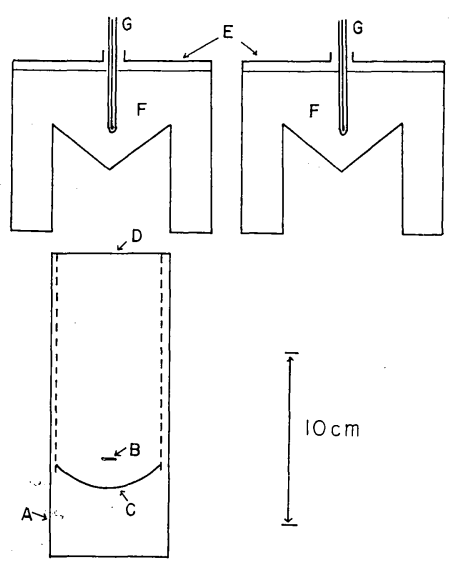

Fig. 1 The radiometer and the radiators. $\mathrm{A}$ : radiometer, $\mathrm{B}$ : sensor, $\mathrm{C}$ : concave mirror, D: polyethylene thin film, E: water tank used as the radiator for calibration, F: water. The incident radiation is reflected by the concave mirror and reaches the sensor. The difference of the water temperature between two water tanks is $15-20^{\circ} \mathrm{C}$.

\section{Measurement of downward radiation of wavelength between 8-17 $\mu \mathrm{m}$ from the direction of zenith above the city}

\subsection{The reason for measuring the radiation of} the wavelength between 8-17 $\mu \mathrm{m}$

In the case of the measurement of the downward radiation flux by the common radiometer, the radiations of the wavelength between 2-80 $\mu \mathrm{m}$ from all the directions are measured. Of these radiations, those whose wavelengths are less than about $8 \mu \mathrm{m}$ and those whose wavelengths are more than about $13 \mu \mathrm{m}$ are almost equal respectively to the radiation energy within the two ranges of the wavelength of the black body radiation at the surface temperature. Also, note that the value of the downward radiation between the wavelength of $8-13 \mu \mathrm{m}$ is small.

Thus, even if the pollutants emits the downward radiations whose wavelengths are between 2-80 $\mu \mathrm{m}$, of these radiations, only those whose wavelengths are about between $8-13 \mu \mathrm{m}$ can be sensed as the additional radiation by the radiometer installed on the ground. Because of this, we know that it is considerably difficult to detect the effect of the pollutants from the value of the downward radiation flux measured by the common radiometer. However, if the range of the wavelength to be measured is limited to that of $8-13 \mu \mathrm{m}$, since the radiation from the water vapor is small within this range of wavelength, it seems easy to detect the radiation from the pollutants.

Thus, the author has decided to carry forward this research according to the following procedure. Firstly, to measure the downward radiations within the range of $8-13 \mu \mathrm{m}$, and clarify the relationship between the measured value and the visibility; and secondly, to calculate the value of the downward radiation flux by adding the value of the energy of the black body radiation at the surface temperature within the wavelength range except $8-13 \mu \mathrm{m}$, and to determine the relationship between the calculated value and the visibility.

\subsection{Method of measurement}

For the measurement of the downward radiation within the wavelength range of $8-13 \mu \mathrm{m}$, the commercially available radiation thermometer was used as the substitute for the radiometer. This radiation thermometer is capable of measuring the radiations within the wavelength range of $8-17 \mu \mathrm{m}$, but it has a cylindrical body, and so it is impossible to cover the radiations coming from all the directions with this radiation thermometer.

Thus, in actual measurement, this radiation thermometer is used only for measuring the downward radiation from the direction of the zenith. The experiments for determining the calibration constant have been conducted outdoors both immediately before and after the measurement of the radiation, and the average of the two calibration constants is used for the calculation of the radiation.

In the following, the explanation will be made as to the method of the calibration of the radiometer. Fig. 1 shows the radiometer to be used for the measurement and two water tanks to be used as the radiators. These water tanks are made of copper, and their bottoms are painted black. These water tanks contain the water, but the temperature of the water in one water tank differs from that of the water in the other tank, and the radiation from the M-shaped bottom of the water tank is used as the reference radiation.

The water tank of this type is similar to that used by Yamamoto and Sasamori in 1954 for the purpose of calibration in measuring the radiation from the atmosphere.

Next, the explanation will be made as to the actual method of calibration. First, as shown in the drawing, one of the two water tanks should 
be set on the radiometer. In this case, the temperature at the bottom of the tank is given as $T_{1}$, and the reading of the microvoltmeter at this time is given as $V_{1}$. When the atmospheric temperature is higher than that of the water in the tank, the value of $T_{1}$ can be determined by adding a certain correction value which is in proportion to the difference between the atmospheric temperature and water temperature to the water temperature. As for the correction value, the same value used by Yamamoto and Sasamori is used.

Of the energies of the black body radiations from the bottom of the tank, the energy of the radiation whose wavelength is within the range of $8-17 \mu \mathrm{m}$ is given as $r_{0} \sigma T_{1}^{4}$. In this case, $r$ is a constant smaller than 1 . The emissivity of the bottom of the water tank within the aforementioned wavelength range is given as $\varepsilon$. The transmissivity of the radiation passing through the polyethylene thin film covering the entrance of the radiometer and the water vapor in the cylinder of the radiometer is given as $t$. In this case, of the radiations emitted from the bottom of the water tank, the radiations whose wavelengths are within the range of $8-17 \mu \mathrm{m}$ reaching the sensing part of the radiometer are $t^{\bullet} \kappa^{\bullet} \varepsilon^{\bullet} \cdot r^{\bullet} \sigma T_{1}{ }^{4}$. In this case, $\kappa$ is a constant representing the ratio of the radiations which can be covered by the radiometer, out of the radiations emitted in all directions from the bottom of the water tank, and is the geometric coefficient related with diameter of the entrance of the radiometer.

After reading the value of $V_{1}$, the other water tank is used. Where the temperature of the bottom of this water tank is given as $T_{2}$, the radiation reaching the sensor can be given as $t^{\bullet} \kappa^{\bullet} \varepsilon^{\bullet} \cdot r^{\bullet} \sigma T_{2}{ }^{4}$. In this case, the reading of the meter is given as $V_{2}$. Since the difference between the both radiations is in proportion to $\left(V_{1}-V_{2}\right)$, we obtain

$$
t \cdot \kappa \cdot \varepsilon \cdot r\left(\sigma T_{1}{ }^{4}-\sigma T_{2}{ }^{4}\right)=k\left(V_{1}-V_{2}\right)
$$

where $k$ denotes the proportional constant concerning the electrical circuit. Where $K$ given in the following equation is called the calibration constant, we obtain

$$
K=\frac{k}{t \cdot \kappa \cdot r}=\frac{\varepsilon\left(\sigma T_{1}{ }^{4}-\sigma T_{2}{ }^{4}\right)}{V_{1}-V_{2}}
$$

As for the value of $\varepsilon$, the value of 0.963 has been obtained through the indoor experiment conducted separately. In this experiment, the radiation from the surface of finely crushed ice is used as the reference radiation, and the emissivity of the surface is assumed to be 1.00 . When the values for $T_{1}, T_{2}, V_{1}$ and $V_{2}$ are given, the value of $K$ can be determined by the equation (2).

Next, the explanation will be made as to the method for measuring the downward radiation from the atmosphere by directing the radiometer towards the zenith. In the case of this method, only one water tank is used. Like the case of the calibration, the water tank should first be set on the radiometer. In this case, the temperature of the bottom of the water tank is given as $T_{0}$, and the reading of the meter at this time is given as $V_{0}$. Also, in this case, the value of radiation reaching the sensor is $t^{\bullet} \kappa^{\bullet} \varepsilon^{\bullet} \cdot r^{\bullet} \sigma T_{0}{ }^{4}$.

Then, the water tank is removed, and the radiation from the zenith should be measured, and the reading of the meter at this time is given as $V$. When the radiation from the direction of zenith whose wavelength is within the range of 8-17 $\mu \mathrm{m}$ which can be covered by the radiometer is assumed to be $I_{\Delta \lambda}$, the radiation reaching the sensor of the radiometer is $t \cdot I_{\Delta \lambda}$. Therefore, we obtain the following equation in the similar manner to the case of equation (1).

$$
\begin{aligned}
& t \cdot \kappa \cdot \varepsilon \cdot r \cdot \sigma T_{0}{ }^{4}-t \cdot I_{\Delta \lambda}=k\left(V_{0}-V\right) \\
\therefore \quad & I_{\Delta \lambda}=\kappa \cdot \varepsilon \cdot r \cdot \sigma T_{0}{ }^{4}-\frac{k}{t}\left(V_{0}-V\right)
\end{aligned}
$$

In equation (3), $I_{\Delta \lambda}$ represents the radiation from the above, but in the following discussion, instead of considering $I_{\Delta \lambda}$ alone, we are going to discuss $I_{\Delta \lambda} / B_{\Delta \lambda}$ which is the ratio of $I_{\Delta \lambda}$ to $B_{\Delta \lambda}$. Here, $B_{\Delta \lambda}$ represents the radiation whose wavelength is within the range of $8-17$ $\mu \mathrm{m}$, and can be covered by the radiometer, out of the black body radiation at the surface temperature. The idea of considering the ratio between $I_{\Delta \lambda}$ and $B_{\Delta \lambda}$ is similar to the idea of considering the ratio between the downward radiation and the black body radiation at the surface temperature in analyzing the downward long-wave radiation measured on the ground.

When the surface temperature is given as $T_{a}$, $B_{\Delta \lambda}$ can be expressed by the following equation:

$$
B_{\Delta \lambda}=\kappa \cdot r \cdot \sigma T_{a}{ }^{4}
$$

Therefore, from the equations (2) and (3), the value of $I_{\Delta \lambda} / B_{\Delta \lambda}$ can be expressed by the following equation:

$$
\frac{I_{\Delta \lambda}}{B_{\Delta \lambda}}=\frac{1}{\sigma T_{a^{4}}}\left\{\varepsilon \cdot \sigma T_{0}^{4}-K\left(V_{0}-V\right)\right\}
$$

The values of $T_{a}, T_{0}, V_{0}$ and $V$ on the right side 
of the equation (4) can be measured, and since the value of $K$ can be obtained by the aforementioned method, the value of $I_{\Delta \lambda} / B_{\Delta \lambda}$ can be obtained from the equation (4).

\subsection{Result of measurement}

The measurement was conducted from September through December, 1979 at Akihabara in the central part of Tokyo during 1 to 3 hours after the sunset on cloudless days. As for the value of visibility, the values from routine observation by meteorological observatory at about $1.6 \mathrm{~km}$ distance from the place of measurement of radiation, were used. In a large city like Tokyo, we consider that little temperature inversion occurs at this time.

The values of $I_{\Delta \lambda} / B_{\Delta \lambda}$ obtained through the measurement are plotted on Fig. 2. The dispersion of the plotted points is considered depending on the degree of the concentration of the pollutants in the atmosphere. The dotted line is drawn by connecting the points at which the values of $I_{\Delta \lambda} / B_{\Delta \lambda}$ to any value of the water vapor pressure are considered to become the smallest. Those points on or in the vicinity of this dotted line represent the measured values when the visibility is $30-35 \mathrm{~km}$. Thus, we may consider that the dotted line represents the values of $I_{\Delta \lambda} / B_{\Delta \lambda}$ at the time when the pollutants are not existing.

If the value of the downward radiation at the time when the pollutants are not existing is assumed to be $I_{\Delta \lambda 0}$, the dotted line represents

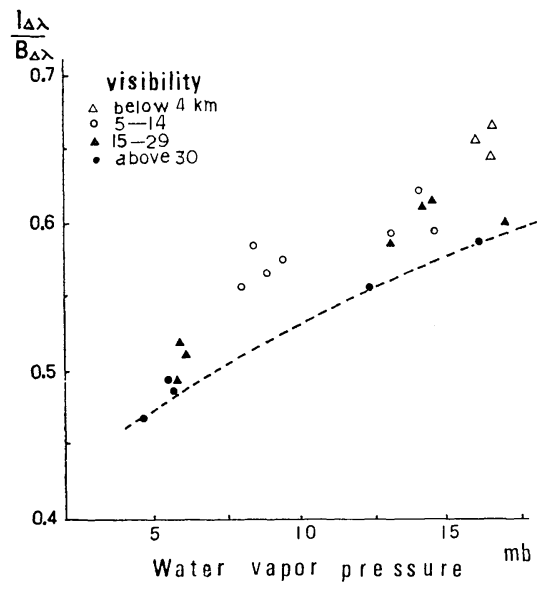

Fig. 2 The values of $I_{\Delta \lambda} / B_{\Delta \lambda}$ obtained from the measurement in Tokyo. Dotted line: estimated value of $I_{\Delta \lambda} / B_{\Delta \lambda}$ at the time when the pollutants are not existing.

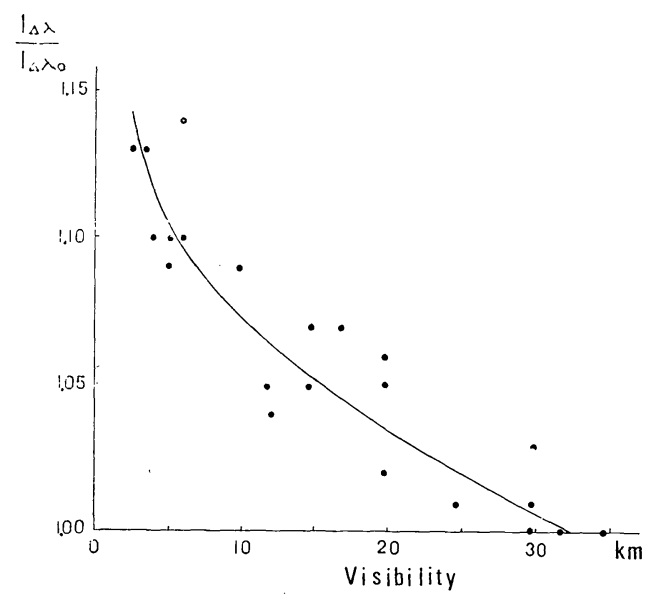

Fig. 3 The relationship between the value of $I_{\Delta \lambda} / I_{\Delta \lambda 0}$ and the visibility at night.

the value of $I_{\Delta \lambda 0} / B_{\Delta \lambda}$. If we obtain the ratio between the value of $I_{\Delta \lambda} / B_{\Delta \lambda}$ obtained through the measurement conducted at the time when the effect of the pollutants is existing and the value on the dotted line to the value of the water vapor pressure at that time, that is, $\left(I_{\Delta \lambda} / B_{\Delta \lambda}\right) /\left(I_{\Delta \lambda 0}\right)$ $\left.B_{\Delta \lambda}\right)=I_{\Delta \lambda} / I_{\Delta \lambda 0}$, we are able to know the effect of the pollutants on the radiation from the direction of the zenith.

Fig. 3 shows the relationship between the value of $I_{\Delta \lambda} / I_{\Delta \lambda 0}$ and the visibility measured at that time. In this figure, the solid line represents the average value of the plotted points. From Fig. 3 , we can see that the radiation $I_{\Delta \lambda}$ from the direction of the zenith increases markedly as the visibility decreases. For instance, when the visibilities are $20 \mathrm{~km}, 10 \mathrm{~km}$ and $4 \mathrm{~km}$, the radiation increases by about $3.5 \%, 7.3 \%$ and $11.5 \%$ respectively.

\section{Measurement of the radiation in country district}

In parallel to the measurement of the radiation in Tokyo, we have measured the radiation in Okabe, about $70 \mathrm{~km}$ in the northwest from Tokyo, by the same method which we have used in Tokyo. The place of measurement is located in the middle of the country district, and surrounded by a wide vegetable-growing field. For this measurement, the same radiometer as that used in Tokyo was used. Also, in order to examine the degree of temperature inversion, the temperatures at the levels of $1 \mathrm{~m}$ and $20 \mathrm{~m}$ above the ground were measured.

Fig. 4 shows the result of the measurement 


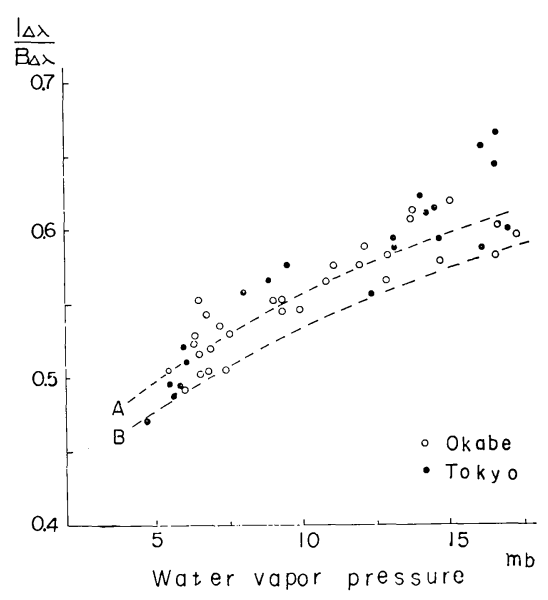

Fig. 4 The value of $I_{\Delta \lambda} / B_{\Delta \lambda}$ obtain from the observation in Okabe. The values in Tokyo plotted in Fig. 2 are also plotted in this figure.

Line A: mean curve of observed values in Okabe.

Line B: estimated value of $I_{\Delta \lambda} / B_{\Delta \lambda}$ at the time when the temperature inversion is not existing in Okabe.

conducted in Okabe. The measured values listed in Fig. 2 are also listed in Fig. 4 so that the result of measurement in the country district can be compared with that of measurement in the city. According to Fig. 4, it seems that there are no significant differences between the average of $I_{\Delta \lambda} / B_{\Delta \lambda}$ values measured in the large city and the average of $I_{\Delta \lambda} / B_{\Delta \lambda}$ values in a country district. Thus, it seems that the same can be said as to the downward radiation flux whose wavelength is within the range of $2-80 \mu \mathrm{m}$ which is commonly measured.

In considering the downward radiation at night in the country district, however, it is necessary to consider the effect of the temperature inversion.

According to the researches by Yamamoto and Sasamori (1954), Saito (1961) and Fujimoto (1975), the value of $R / \sigma T_{a}^{4}$ at the time when the temperature inversion is severe is large by about $10 \%$ than that at the time when the temperature inversion is not existing even when the water vapor pressure remains unchanged. Thus, in estimating the additional radiation from the comparison of the values of radiations in the city and country district; it is necessary to consider the effect of the temperature inversion.

As for the measurements which we have con- ducted in the country district, the temperature inversions have been observed in almost all the cases. On the other hand, according to the estimation based on the results of the past researches concerning the weather conditions in the cities, it can be considered that the temperature inversions have not been existing at the times when the measurements have been conducted in Tokyo.

In order to examine the change in the value of $I_{\Delta \lambda} / B_{\Delta \lambda}$ depending on the degree of the temperature inversion, we have measured the radiation and the temperature inversion from time to time during the time period ranging from about 2 hours before the sunset to 3 hours after the sunset in each of the selected cloudless and breeze-blowing three days. Fig. 5 shows the results of these measurements. In this graph, $\Delta \theta$ measured by horizontal scale represents the value obtained by deducting the value of temperature at the level of $1 \mathrm{~m}$ above the ground from that at the level of $20 \mathrm{~m}$ above the ground. The height of $20 \mathrm{~m}$ is not always enough to measure the degree of the temperature inversion, but it is enough to know the general tendency of the temperature inversion. The scale of its ordinate represents the rate of multiplication of $I_{\Delta \lambda} / B_{\Delta \lambda}$ when the value of $I_{\Delta \lambda} / B_{\Delta \lambda}$ is assumed to be 1.00 when $\Delta \theta=0$ in Fig. 5. In this figure, the three dotted lines represent respectively the average of the changes in the value of $I_{\Delta \lambda} / B_{\Delta \lambda}$ in each day. The solid line shows the average of the three dotted lines. The dispersion of the measured values for the country district shown in Fig. 4 is considered to have been resulted probably from the variation of temperature inver-

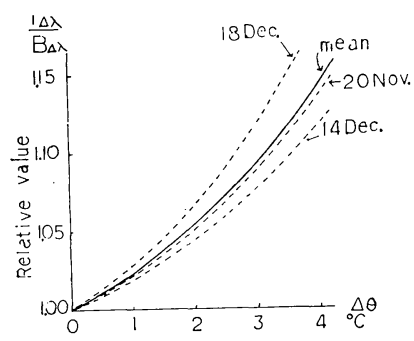

Fig. 5 The change in the value of $I_{\Delta \lambda} / B_{\Delta \lambda}$ depending on the degree of the temperature inversion. $\Delta \theta$ : temperature difference between $20 \mathrm{~m}$ high and $1 \mathrm{~m}$ high above the ground. The scale of ordinate is taken to be 1.00 where $\Delta \theta=0$. Dotted line: the average in each day. Solid line: the average of the three dotted lines. 
sion.

In Fig. 4, the dotted line A represents the average condition of the measured values for the country district. If there is no inversion of temperature, when $\Delta \theta=0$, what does the curve representing the relationship between $I_{\Delta \lambda} / B_{\Delta \lambda}$ and the water vapor pressure look like? Now, let's presume roughly what such curve look like. In the case of the measurement in the country district, the total average value of $\Delta \theta$ is $1.7^{\circ} \mathrm{C}$. The rate of increase in the value of $I_{\Delta \lambda} / B_{\Delta \lambda}$ caused by the inversion to this value of $\Delta \theta$ is $4.5 \%$ according to the solid line in Fig. 5. Therefore, when the values represented by the dotted line $\mathrm{A}$ are reduced equally by $4.5 \%$, we obtain the dotted line $B$, which can be considered to represent the rough value of $I_{\Delta \lambda} / B_{\Delta \lambda}$ at the time when the temperature inversion is not existing.

When we compare the dotted line B with the dotted line show in Fig. 2, we can notice that the values represented by the former line are very close to those represented by the latter line. From this, it can be said that the dotted line in Fig. 2 is good enough to show the relationship between the water vapor pressure and the value of $I_{\Delta \lambda} / B_{\Delta \lambda}$ at the time when the pollutants are not existing.

\section{Calculation of the rate of increase in down- ward radiation with decrease of visibility}

Now, based on the relationship between the visibility and the rate of increase in the radiation within the range of $8-17 \mu \mathrm{m}$ falling from the direction of the zenith caused by the pollutants shown in Fig. 3, let's determine, by calculation, the relationship between the visibility and the rate of increase in the radiation flux within the range of the wavelength of $2-80 \mu \mathrm{m}$ falling on the ground from all the directions.

Fig. 6 shows the general distribution, by wavelength, of the energy of the radiation flux $R$ from the atmosphere falling on the ground when the surface temperature is $T_{a}$ (For example, refer to the result of the researches by Yamamoto in 1950 and Roach and Slingo in 1979). From Fig. 6, we obtain

$$
\begin{aligned}
R & =B+(C+D) \\
& =(A+B)\left\{\frac{B}{A+B}+\frac{C+D}{A+B}\right\}
\end{aligned}
$$

As stated previously, since $A+B=r^{\cdot} \sigma T_{a}^{4}$, we obtain

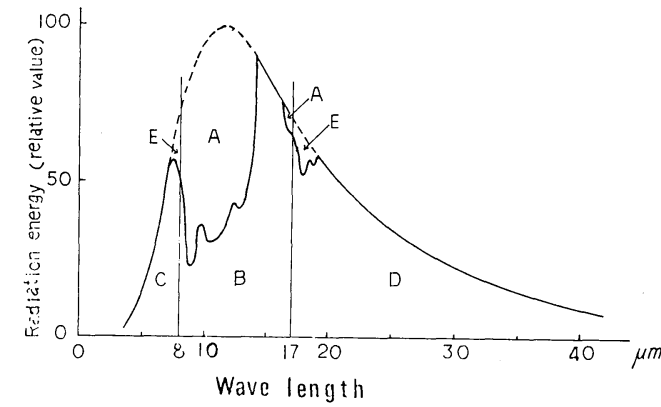

Fig. 6 Solid line: General pattern of the spectral distribution of the energy of the radiation flux from the atmosphere. The downward radiation flux $R=\mathrm{B}+\mathrm{C}+\mathrm{D}$. Dotted line: black body radiation at the surface temperature of $290^{\circ} \mathrm{K}$ which approximate to the average of observed values. When the additional downward radiation from pollutants exists, only a part of $\mathrm{B}$ increases approximately. The value of $r$ is expressed as $(\mathrm{A}+\mathrm{B}) / \sigma T_{a}{ }^{4}$.

$$
\begin{aligned}
& C+D=\sigma T_{a}^{4}-(A+B)-E \simeq \sigma T_{a}^{4}-(A+B) \\
& \quad=\sigma T_{a}^{4}(1-r) .
\end{aligned}
$$

Therefore, we obtain

$$
R \simeq r \cdot \sigma T_{a}^{4}\left\{\frac{B}{A+B}+\frac{1-r}{r}\right\}
$$

In introducing the equation (5), $E$ is disregarded as its values is small compared with others, but it does not seem that the disregard of $E$ gives any significant effect on the final result of calculation.

The approximate value of $B /(A+B)$ at the time when the pollutants are not existing is obtained by the following method. When we compare the equation (5) with the well-known Brunt's formula $R=\sigma T_{a}^{4}(\alpha+\beta \sqrt{e})$ concerning the experiment for the radiation from the atmosphere, we obtain

$$
r\left\{\frac{B}{A+B}+\frac{1-r}{r}\right\}=\alpha+\beta \sqrt{\bar{e}}
$$

Since the values of $r, \alpha$ and $\beta$ are given as the constants, when the value of $e$ is given, from the above equation, we can obtain the value of $B /(A+B)$ at the time when the pollutants are not existing.

Now, let's consider the variation rate of $B /(A+B)$. which depends on the variation of visibility. $B /(A+B)$ is the quantity concerning the radiation flux within the range of the wavelength of $8-17 \mu \mathrm{m}$ falling on the ground from all the directions, while the value of $I_{\Delta \lambda} / B_{\Delta \lambda}$ obtained through the measurement of this time 


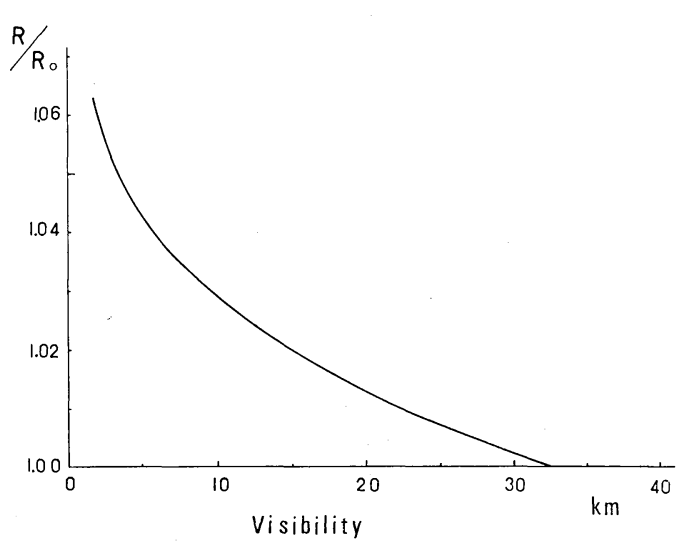

Fig. 7 The value of $R / R_{0}$ to various visibility at night.

$R_{0}$ : downward radiation flux from the atmosphere at the time when the aerosols are not existing.

$R$ : downward radiation flux in the case of presence of the pollutants.

is the quantity concerning the radiation within the same range of wavelength falling from the direction of the zenith. In this case, however, we may assume that the increase rates for $B / A+B$ and $I_{\Delta \lambda} / B_{\Delta \lambda}$ which are dependent on the decrease of visibility are proximately equal to each other. Thus, we can calculate the increase rate of $B /(A+B)$ depending on the decrease of the visibility using the value represented by the solid line in Fig. 3 .

The example of calculations is as shown in the following. In equation (5), as for the value of $r$, of the black body radiation energy at the average value of observed surface temperature, the ratio of the energy of the radiation within the range of the wavelength of $8-17 \mu \mathrm{m}$ is obtained by the spectral distribution chart of the energy of the black body radiation (Fig. 6). This value is found to be 0.533 . Now, let's calculate the value of $B /(A+B)$ at the time when the visibility is $32 \mathrm{~km}$ or more than that, by equation (6). In this calculation, as for the values of $\alpha$ and $\beta, \alpha=0.51$ and $\beta=0.066$ which are given by Yamamoto (1950) are used. As for the value of $e, 12 \mathrm{mb}$ which is the average of the measured values is used. Then, we obtain $B /(A+B)=0.510$ from the equation (6). When the value of $R$ is given as $R_{0}$ where the visibility $32 \mathrm{~km}$, we obtain $R_{0}=r^{\circ} \sigma T_{a}^{4} \times 1.386$. Then, let's determine the value of $R$ where the visibility decreases while the values of $T_{a}$ and $e$ remain unchanged. For example, when the visibility is
$20 \mathrm{~km}$, as explained in Fig. 3, the value of $B /(A+B)$ becomes larger by $3.5 \%$, we obtain $R=r^{\cdot}{ }_{\sigma} T_{a}^{4}(0.510 \times 1.035+0.876)=r^{*} \sigma T_{a}^{4} \times 1.404$. In this case, $R / R_{0}=1.013$, and so the increase rate of the downward radiation flux by the pollutants is $1.3 \%$.

The values of $R / R_{0}$ to various visibilities are shown in Fig. 7. Through the foregoing procedure, we have clarified the relationship between the fall of visibility and the increase rate of the downward radiation flux.

\section{Conclusion}

The relationship between the increase rate of the downward radiation flux and the visibility is obtained by calculation, based on the relationship between the visibility and the downward radiation within the range of the wavelength of 8-17 $\mu \mathrm{m}$ from the direction of the zenith which has been measured during the nighttime in Tokyo (see Fig. 7). According to the result of this calculation, the effect of the radiation by the pollutants may be considered to be insignificant where the visibility is more than $32 \mathrm{~km}$, but the quantity of radiation begins to increase gradually as the visibility becomes lower than the abovementioned level.

For example, when the visibility is $2 \mathrm{~km}$, it is known that the downward radiation flux increases by about $6.0 \%$. In many instances, the visibility at night in Tokyo is $5-15 \mathrm{~km}$. Under such conditions, the increase rate of radiation flux is $2-4 \%$. This range of percentage is close to that obtained by Fujimoto in 1975. In general, the error in the measurement of the downward radiation flux from the atmosphere using the commonly used radiometer is $3-4 \%$, and so it seems rather difficult to measure quantitatively the increase rate of the radiation caused by the pollutants by measuring it directly.

\section{Acknowledgements}

The completion of this research by the author owes greatly to Prof. Giichi Yamamoto who has given advices to the author for many years. The author would like to express its hearty thanks to him for his kindness, and pray for the repose of his soul.

\section{References}

Aida, M. and M. Yaji, 1979: Observations of atmospheric downward radiation in the Tokyo area. Boundary Layer Meteorology, 16, 453465. 
Fujimoto, F., 1975: Influence of atmospheric pollu- Yamamoto, G., 1950: On nocturnal radiation: Part tion of the long wave radiation. Geophys. Mag., 37, 207-256.

Saito, T., 1961: Empirical formula of atmospheric radiation. J. Met. Res., 13, 206-215.

Roach, W. T. and A. Slingo, 1979: A high resolution infrared radiative transfer scheme to study the interaction of radiation with cloud. Quart. J. Roy. Met. Soc., 105, 603-614.

II. J. Meteor. Soc. Japan, 28, 11-20.

and T. Sasamori, 1954: Measurement of atmospheric radiation. Sci. Rep. Tohoku Univ., Ser. 5, Geophys., 6, 19-31.

1957: Estimation of additional downward radiation from aerosols over large cities. $J$. Meteor. Soc. Japan, The 75th Anniversary Volume, 1-4.

\section{大気污染物質による下向き長波放射の増加率と視程との関係}

\section{斉藤 隆 幸 \\ 埼玉工業大学}

都市の大気污染物質による下向き長波放射は非常に小さいので：地上における通常の放射の観測值から，その 量を定量的に検出することはむずかしい。しかし水蒸気の射出率の小さい波長範囲では，そのよらな付加的放射 の検出は比較的に容易となることが予想される。それ故, 8-17 $\mu \mathrm{m}$ の範囲の放射を感じ得る筒型の放射計を上 方に向け, 夜間, 都心において天頂方向からの放射を測定した。その結果, その放射は視程の減少とともに顕著 に増加することがみとめられた。

つぎにその測定結果をもとにして，計算により通常観測される下向き放射 flux に拈よぼす污染物質の影響と 視程との関係を求めた。図 (Fig. 7) に示されているよらに, 視程の減少とともに下向き放射は徐徐に増加し, 例えば視程が $2 \mathrm{~km}$ の場合, 同一水蒸気量に対して, その増加率は約 6.0 パーセントとなる。

また比較のために田園地域でも同様の観測を行った。その結果から，同一水蒸気量に対する $R / \sigma T a^{4}(R$ は地． 上に拈ける下向き放射 flux, $T a$ は地表温度)の值は, 両地域に拉いて殆ど差がないであろらといらことが予想さ れる。この事は都市に敃いて付加的放射がないといらことにはならない。田園地域に拈いては気温の逆転が $R /$ $\sigma T_{a}{ }^{4}$ の值を大きくしているからである。 